\title{
Shortcomings in Current Practices for Decision-Making Process and Contaminated Sites Remediation
}

\author{
Mehran Naseri Rad', Ronny Berndtsson ${ }^{2}$ \\ ${ }^{1}$ Division of Water Resources Engineering \& Centre for Middle Eastern Studies, Lund University \\ Box 118, SE-221 00 Lund, Sweden \\ mehran.naseri_rad@tvrl.lth.se; ronny.berndtsson@tvrl.lth.se
}

\section{Extended Abstract}

As a result of the huge economic and industrial development that human has been experiencing for decades or centuries, there are millions of potentially contaminated sites around the globe. Potentially contaminated sites are those which industrial, agricultural, mining and waste containment activities with potential to contaminate soil and groundwater has taken place in. A small number of these contains dangerous levels of contamination and much fewer have been remediated so far. As an example, in Europe, according to European Environmental Agency in 2014 there are some 2,500,000 potentially contaminated sites with an estimated number of about 342,000 sites that contain significant contamination needing remediation., of which just about $15 \%$ have been remediated [1]. The situation is probably much worse when it comes to most developing countries. Here, there is usually no priority regarding remediation even though it is well known that contamination is related to public health. In these countries, there is often a lack of data regarding contaminated sites and levels of contamination. Sometimes, authorities deny any contamination and in any case no actions may be taken for the use of specific water supply wells. In some cases, the reason may be inefficient regulation and lack of funding for surveying and remediation [2].

A basic problem is that the remediation process of contaminated soil and groundwater is a complex and multidisciplinary issue and there are no efficient and reliable general tools to help in the decision-making practise. The different kinds of possible contaminants and variation of soil parameters result in a physical system with many degrees of freedom. To this are added the social, economic, and environmental aspects needed to be considered when making sustainable decisions for the remediation activities.

In this study, generally available decision-making tools, systems and methods for contaminated site remediation, are critically reviewed first. Secondly, the importance of incorporating contaminant transport properties for different chemicals in the decision-making process is exemplified for a case study in Iran. In this case study an unconfined aquifer contaminated by selenium, cadmium and antimony is modelled, aiming to find solutions for dealing with the contamination. Due to the complex situation at the site, which is usually the case in reality, the results showed why current tools are rarely used for decision making process in contaminated site management and it is essential to make better models and integrate them to make better decisions. After this case study, the difference in results by different multi-criteria decision-making algorithms is shown.

The main objective of this study is to show shortcomings in current practices of decision making for contaminated sites remediation. It is shown that we need more detailed, practical and trustworthy tools to base our decisions on. It is shown that it is necessary to incorporate knowledge on contaminant transport modelling into the decision-making process in a proper way depending on the real complexity that is always involved.

\section{References}

[1] European Environment Agency (2014), "Progress in management of contaminated sites," Prod-ID: IND-10-en. Also known as: LSI 003. Created 04 Mar 2014. Copenhagen, Denmark. [Online]. Available: https://www.eea.europa.eu/data-and-maps/indicators/progress-in-management-of-contaminated-sites-

3/assessment

[2] I. Radelyuk, K. Tussupova, K. Zhapargazinova, M. Yelubay, and M. Persson, "Pitfalls of Wastewater Treatment in Oil Refinery Enterprises in Kazakhstan — A System Approach,” pp. 1-20, 2019. 